\title{
Big Data Analysis of Financial Based on Mapping-Inversion Principle
}

\author{
Xuenan Qiu \\ Australian National University \\ Canberra ACT 0200, Australia \\ Sunny1507@163.com
}

\author{
Ping $\mathrm{He}^{*}$ \\ Liaoning Police College \\ No.260, Yingping Road, Dalian, 116036, China \\ heping2000@163.com
}

\begin{abstract}
How to apply big data mining to financial management and decision-making is an urgent problem to be solved in the research of financial management and decisionmaking. In this paper, the relation mapping-inversion principle is applied to financial management decision-making, and a novel financial management big data mining method, that is, the learning mode of financial data mapping and knowledge inversion, is established. The basic framework of this financial management model is mapping from data relations to management rules, and inverting from management rules to decision-making mode. At the same time, the relationship between financial data, knowledge and experience are analyzed from the perspective of financial management decision support system, and the significance and function of financial big data management are analyzed by establishing a learning mechanism of mutual integration.
\end{abstract}

Keywords-Financial management; big data; mappinginversion; learning mechanism; experience and knowledge

\section{INTRODUCTION}

The development of modern information technology puts forward new requirements for enterprise financial management and decision-making with the deepening of financial informatization construction. Under the background of the increasing scale of enterprise financial data, whether it is the financial planning and management of enterprises, or the effective evaluation of the quality of accounting information, as well as the financial decisions in the operation process of enterprises in various periods, a large amount of data information with different forms of storage has been accumulated [1]. Due to the multifarious data presented by financial information, it has become a very difficult task to discover valuable knowledge and achieve the purpose of serving the financial decision-making of enterprises. Enterprise financial management needs new and more effective means to exploit all kinds of information resources to play its due financial decision potential. Under this background, financial OLAP technology, financial data mining and knowledge discovery came into being. It is these three new data analysis technologies based on big data that provide new research methods and analysis tools for corporate financial decisions, which are conducive to improving the accuracy and timeliness of corporate financial decisions and reducing the risk of corporate business decisions.
This paper introduces the significance, characteristics and functions of financial big data mining from the perspective of the actual demand of enterprise financial management and decision-making, and puts forward a novel learning model that satisfies the principle of data mapping and knowledge inversion. The credibility of the learning model is verified through the experience perception and rational analysis of financial management.

This paper is organized as follows. Section 2 presents the practical significance and role of financial big data. Section 3 provides a new big data method -- data mapping and experience inversion, and established a model of financial management and decision-making based on experience diagnosis and big data learning. Section 4 introduces how to reasonably handle data analysis and experience perception in big data mining. Finally, Section 5 draws a conclusion and further work.

\section{THE SIGNIFICANCE AND ROLE OF FINANCIAL DATA MINING}

\section{A. Idea of financial decision-making from data to knowledge}

As we know, financial management and decision-making determine the success or failure of enterprise operation, while the credibility of financial management and decision-making depends on financial big data analysis. In today's financial decisions, such as investment analysis, cost analysis, allocation budget, etc., the use of a single financial data analysis can no longer meet the needs of business decision-making. Today's corporate financial decisions must have diversified, multi-level, multi-value information characteristics. That is to say, in financial decision-making, multiple elements such as the relationship between finance and enterprise operation status, data characteristics of finance and multiple stakeholders, and information of mutual influence between finance and enterprise internal and external environment should be integrated to form an idea of management and decision-making with big data mining and knowledge discovery.

Financial data mining has become a hot topic of financial management with the development of computer data analysis. The so-called financial big data mining refers to the process of obtaining effective and credible financial decision-making information from financial big data [2]. The data attributes in financial big data are characterized by multi-dimension, multilevel, multi-economy and multi-management behaviors. 
Therefore, data mining methods with different characteristics can be adopted. For example, clustering and classification methods, association rules, time series analysis, etc..

In addition, traditional data analysis can let financial personnel and enterprise decision makers know that through a variety of financial statements can be obtained by the enterprise financial decision-making needs of the deterministic content, called financial process knowledge. However, this kind of financial knowledge only reflects the deterministic attribute of accounting information, while the purpose of financial big data mining is how corporate financial decision makers acquire financial management knowledge and financial decisionmaking mode through big data mining. [3] In other words, rules and patterns for dealing with uncertain financial information should be derived from the underlying correlation characteristics. For traditional financial data analysis methods, it is impossible to achieve this purpose.

\section{B. The role of big data in financial decisions}

The characteristics of multi-dimensional, extensive, complex, uncertain and dynamic of enterprise financial data are more and more obvious with the non-equilibrium effect of China's market economy on enterprise competition mechanism. Therefore, big data plays an increasingly prominent role in financial decision-making. It is reflected in the following aspects:

\section{1) Improved the information processing function of} financial management

The basic mode of traditional enterprise financial management is to conduct data query and analysis according to financial statement information to complete daily processing of various accounting business. However, the data obtained from financial statements lack the ability to analyze, and enterprise decision-makers are unable to compare and analyze the relevant data of a certain production and operation subject from multiple angles with the support of a large amount of historical data, so as to obtain scientific decision analysis results. Financial big data analysis can improve the function of enterprise financial decision analysis. [4]

\section{2) Helps reduce the risk of financial decisions}

The multi-dimensional, extensive and dynamic characteristics of financial information bring great uncertainty to corporate financial decision-making. For example, internal data reflecting enterprise objectives, enterprise operation status and personnel organization status are called internal information; data reflecting related parties of enterprises such as customers and suppliers are called external information; in addition, data characteristics of social and economic elements related to enterprise production and operation are called environmental information. These multi-dimensional data uncertainty will form the risk of corporate financial decisions. The key to diagnose and control this risk is to reduce the uncertainty in financial decisions through financial big data analysis.[5] However, traditional financial data analysis can not analyze the uncertainty characteristics of multi-dimensional data. By distinguishing, extracting, sorting out and mining the multi-dimensional information flow in the production and operation of an enterprise, the measurement and evaluation of the uncertainty information useful for financial decisionmaking can be obtained, so as to reduce the risk of financial decision-making.

3) It is conducive to the development of financial artificial intelligence

In financial management, the understanding of financial data will have different meanings due to different business idea. Financial management and decision-making should have the ability to learn data with the expansion of data scale and field of enterprise financial management. In fact, not only can we judge and evaluate the known financial data, but also we can make assumptions and predict the unknown financial data in the financial management decision. Big data mining can use existing data to obtain potential and unknown financial information, so that financial information processing has a strong learning function, So as to realize the intellectualization of financial management and decision-making.

\section{FINANCIAL BIG DATA Mining BASED ON MAPPING- INVERSION}

\section{A. Mapping - inversion model of Data and experience}

Financial big data mining expands the scope of data attributes on the basis of ordinary financial data mining, applies the mapping-inversion principle of data and experience to big data analysis [1], which enhances the learning function of financial management and decision-making.

1) Learning mechanism of data mapping and experience inversion

The so-called financial data mapping is the reflection of various financial status realization process in accounting information. The so-called financial data mapping is the reflection of various financial status realization process in accounting information. Under the mapping of financial data, different enterprises get decision-making mode according to their own financial management experience, and then, get a credible financial decision through the learning process of financial decision-making mode.[6] The basic operating framework is shown in Fig.1:

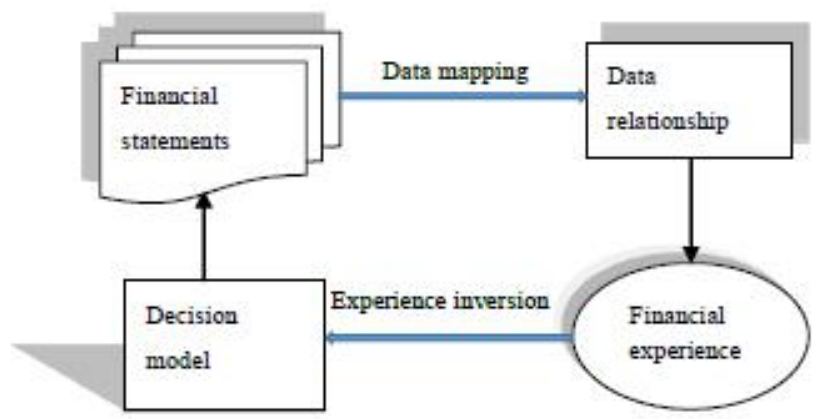

Fig.1. The basic operating framework of mapping and inversion

Taking mapping and inversion learning mechanism as a model of big data mining is of great significance to experience type management decision making. Traditional financial management and decision-making focus on the use of mathematical methods, such as decision tree, regression 
analysis, case-based reasoning, Bayesian network, inductive logic and other methods. However, no matter which data analysis method is adopted, the reliability of data needs to be verified by experience. If mapping and inversion (MAI) learning model is used as the evaluation method of data reliability, the reliability of big data mining can be improved.

The practice of enterprise financial management shows that having data correction function based on experience analysis is one of the main reasons for the rapid growth of an enterprise. Therefore, it can be considered that data mapping and experience inversion is a successful financial management and decision-making model. [7]

\section{B. Big data mining of financial management}

The process of financial big data mining consists of four stages: data hierarchical classification, data preparation, MAI learning, result expression and interpretation. The basic framework is shown in Fig.2:

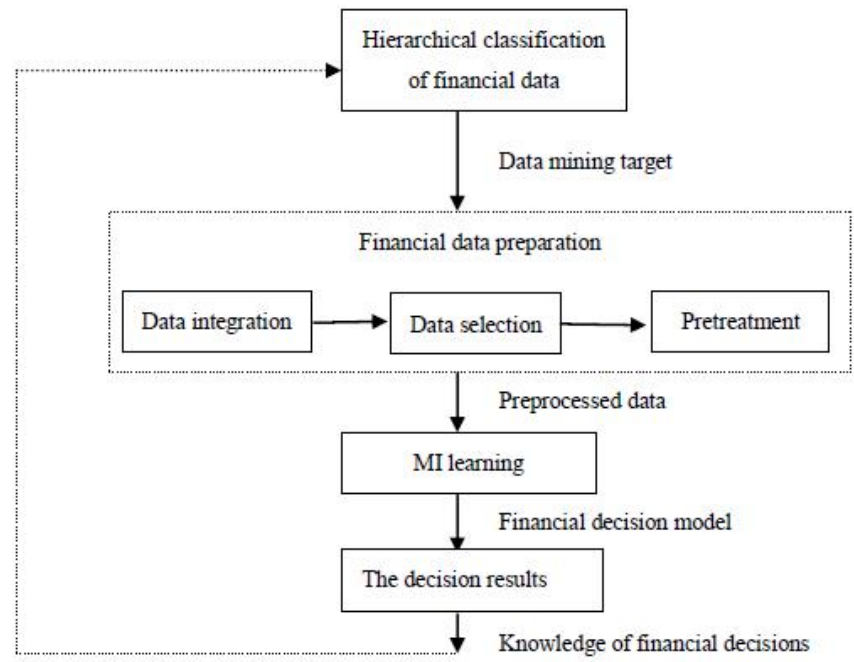

Fig.2. Basic framework of financial big data mining

The practical significance of each module in figure 2 is as follows:

\section{1) Hierarchical classification of financial data}

Financial big data includes financial management nature, dynamic correlation characteristics, influencing factors and other financial decision-making data. Therefore, the premise of this kind of financial big data mining is to effectively classify financial data according to their financial attributes.

\section{2) Preparation of financial data}

This phase is divided into three steps: financial data integration, data selection, data preprocessing. Data integration consolidates data in a multi-file or multi-database running environment. The purpose of data selection is to identify data sets to be analyzed, narrow the processing scope and improve the quality of financial data mining. Preprocessing is to overcome the limitations of financial data mining tools.[8]

\section{3) MAI learning mechanism}

MAI's learning task is to optimize financial data, specifically, to obtain financial data indicators that are most suitable for the realization of corporate goals. The main points included are: a) Generate analytical assumptions for financial decision makers from various financial statements.

b) The data in the financial statements are revised by the financial decision makers according to their experience.

c) The construction of financial relationship factor space.

d) The financial management rules are obtained from the relationship table of financial data based on the fusion analysis of data and experience.

e) Select an acceptable financial management mode according to MAI learning verification.

\section{ANALYSIS AND DISCUSSION}

The results of traditional financial analysis are usually obtained through statistical analysis. The results of financial decisions that rely solely on data are often deviated from the actual operation of enterprises. From the research of theoretical and practical on modern enterprise financial management, a credible financial decision must have a mutual integration of rationality and sensibility. [9]To be specific, data mining is rational and experience diagnosis is perceptual. If empirical diagnosis is included in data mining, the financial decision results can be of great credibility. [10]

In this paper, MAI learning model is introduced into the general financial data mining process to expand the function of data mining. As shown in Fig.3:

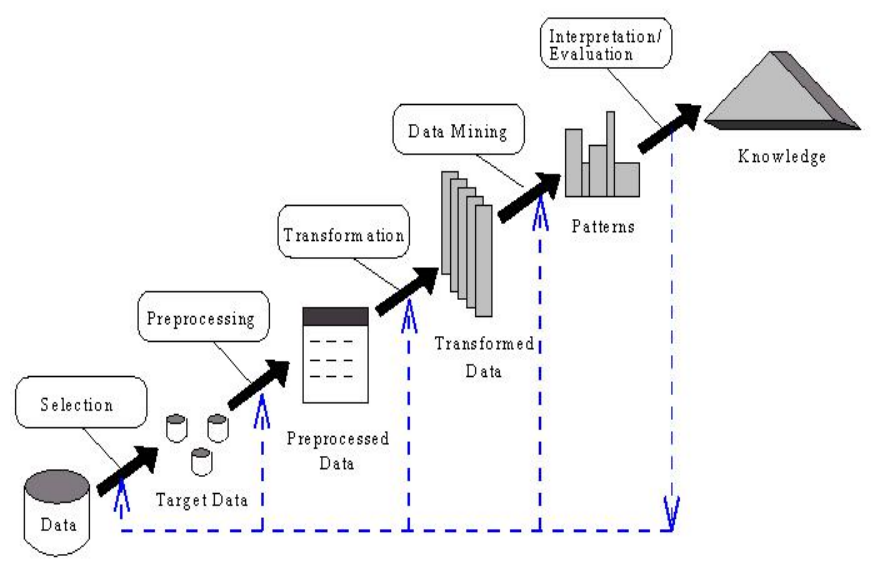

Fig.3. Financial data mining of the experience diagnosis process

We give an experience diagnosis of financial data for each data mining process in Figure 3. The details are as follows:

Data selection based on experience (Selection), financial objective and classification data (Target Data), experience processing and verification (Preprocessing), financial statement preprocessing (Preprocessed Data), data conversion of experience and statistics (Transformation), decision data after transformation (Transformed Data), interpretation and evaluation of data mining (Data Mining), financial decision mode(mode), experience interpretation and evaluation process (Interpretation Evaluation), credible financial rules (Knowledge). 
In the actual process of financial analysis and decisionmaking, the process of fusion decision-making based on experience diagnosis is completed by financial analysts and domain experts. First, the financial analyst is explained the experience assumptions of financial data by the domain expert. Then, the financial analyst introduces the purpose and method of data mining to the domain expert. The understanding of financial data is consistent through the mutual communication between financial analysts and domain experts. [11]

\section{CONCLUSION}

This paper applies relational mapping and inversion principle to big data mining and provides an effective method for enterprise financial management and decision making. The research shows that data mapping and experience inversion is a kind of learning model integrating rationality and sensibility, which fully embodies the intelligent behavior in management and decision-making. From the research of this paper, it can be found that one of the main reasons of enterprise operation risk is the cognition of the practical significance of financial data, and this cognition of financial data is determined by the experience of financial management and decision-making. If we give full play to the role of experience learning in financial management and decision-making, then we can reduce the risk of enterprise financial management to different degrees. In addition, from empirical hypothesis to data analysis is a mapinversion process, and a financial management learning system needs to be established to optimize the selection of financial decision-making mode. In order to build an effective learning system, many problems need to be solved, which is the future research direction.

\section{REFERENCES}

[1] Ke, M. and Shi, Y. Big Data, Big Change: In the Financial Management. Open Journal of Accounting. 2014, Vol. 3, pp.77-82. doi: 10.4236/ojacct.2014.34009.

[2] Tang Guliang, Zhang Shouwen. Big Data: Challenges and Changes of Corporate Financial Management. FINANCE RESEARCH, 2015, Vol.1, pp.59-64.

[3] Zhang Shengyong, Financial Management Innovation: Influencing Factors. Mode Selection and Path Planning, Dongbei University of Finance and Economics, 2016.

[4] Liu Huifang. 2017. A brief discussion on the innovation of enterprise financial management in the era of big data. China International Finance, vol.22, pp.167.

[5] Duma Maobao,Gao Xiuju,Xu Wenjing. Discuss the construction of enterprise financial knowledge management system from the perspective of knowledge management. CONSTRUCTION ECONOMY, 2011, vol.11, pp.83-84.

[6] He Ping. On the Fuzzy, Non-optimum and Trusted. Scientific and Technical Documentation Press. 2016, pp.240-242.

[7] Xiang Jianhong, Huang qiaoxian. Application of data mining technology in financial analysis. Journal of Hubei University of Economics (Humanities and Social Sciences), 2009, vol.6, pp.71-72.

[8] Kang Wei, Research on Enterprise Financial Management Innovation Based on Big Data Utilization - Case Study of Company, Nanchang University, 2018.

[9] Yi Yuye. Talking about Enterprise Financial Management under Big Data Environment. The Guide of Science \& Education, 2018, vol.9, pp.161-162.

[10] Zhu Yanqian. Research on Enterprise Financial Management Innovation Based on the Era of Big Data. Computer and Information Technology, 2018, vol.5, pp.77-79.

[11] Gerard, G., Martine, H. and Alex, P. Big Data and Management. Academy of management Journal, 2014, vol.57, pp.321-326. http://dx.doi.org/10.5465/amj.2014.4002 